\title{
Explore the Consumer Understanding towards Sustainability Is A Key Concept to Unveil the Mystery of Fashion Business
}

\author{
Md.Shamsad Hasnine ${ }^{a^{*}}$, Md. Iftekhar Rahman ${ }^{a}$ MD Tanvir Hasnine ${ }^{b}$ \\ ${ }^{a}$ Faculty of Fashion Design \& Technology, BGMEA University of Fashion \& Technology (BUFT), \\ S.R Tower, 105 Uttara Model Town, Sector 7, Dhaka-1230, Bangladesh \\ ${ }^{b}$ Department of Environmental Engineering, Yildiz technical university, Davutpaşa Campus, Esenler- 34220,
} Istanbul, Turkey.

\begin{abstract}
Previous research into sustainable fashion design has explored the way of reducing the impact of materials and manufacturing mostly, whilst the consumer understanding about sustainable fashion has been ignored. Public understanding is important to show the direction for successful fashion business. Analyzing consumer experience provides an opportunity to make the decision of design which has a direct impact on consumer and garments life-cycle. Documentation and research on consumer wardrobes and history help to address consumer behavior, habits, and perceptions towards sustainability. This paper includes consumer questionnaire, wardrobe inquiry and interviews with consumer aimed to explore public understanding and create awareness of sustainable clothing. At the same time this study provides information to the designer to make fashion more sustainable by taking right design decision. How consumers understanding towards sustainable fashion can influences the designer to design has been highlighted by series of scenarios. For developing sustainable business model how the fashion industry could act from the perception of public behavior and market conditions could be found by further research. It is important to inform the students from fashion design department as well as fashion management about the challenging issues of future fashion business. This study may help the students to become aware about sustainability of fashion which will help them to consider the ethical issues of fashion before creating a collection or selecting a subject for dissertation.
\end{abstract}

Keywords: Sustainable fashion, Consumer understanding, Sustainability, Fashion business.

\section{Introduction}

This paper aims to unveil the opportunities by understanding the consumer's attitude towards sustainable fashion and action within the garment use phase. It will create a new ground for designers to design and develop new garments. When a customer is buying a product he is the most important person who is making the decision of purchasing and also plays an important role on whole life of a garment. Generally fashion designer does not recognize or consider wearer's experiences when they are designing. This paper will find out and discusses those subjects matters relate to choosing and using time of a garment which can help the designer. Although fashion designer needs to know the relationship between consumer and garment, the majority of fashion designers working on new concepts without paying in-depth attention to activities associated with the buying and using phase. Moreover, many designers remain unfamiliar with the specific journey of a garment following the point of purchase (Black et al. 2009). Designer is a significant and central member of a team, ultimately responsible for the initial design ideas, right through to overseeing first samples for selling' (Renfrew $\&$ Renfrew, 2009). Designer works with various people like- textile engineers, fabric merchants, buyers and others. Designer is placed within a central decision-making position, and will be assigned the responsibility for any changes within the design process.

This paper begins with a discussion on a garment's full life and consumer's key activities in the use phase. Considering the habits of consumer during clothing use-phase some principles of Sustainable design for sustainable fashion business have been discussed. The next part discusses the research methods applied to get more information of consumer behavior and which design aspect affects it. Following chapter discuss the findings which will help the designers to extend the longevity of garment and diminish the environmental impact. At the end of this paper study is concluded and further research possibilities are suggested.

\subsection{Garment's lifecycle}

\section{Literature Review}

Designer Without knowing about life cycle of garments, it becomes impossible to him to create a real and lasting change in the way that garments are produced and used. One of the possible ways of increasing sustainability within the field of textiles and clothing is to prolong the use period (Fletcher, 2008; Klepp, 2001).If life of garment could be doubled and one garment less would be produced, the environmental effects will be reduced due to low production and discarding phases could be reduced significantly. This is an 
assumption that in production methods if necessary initiatives could be taken it would not increase the environmental burden. And the longer active use of that specific product would prevent another product from being manufactured. On the other hand increasing the lifetime of clothing would not increase the environmental effects from repair or additional washing and there would be no other recoil effects. Clothing with a long use period may be able to contribute to lower environmental impacts.

Understanding consumer's behavior about a garments life phase (from purchase to disposal) is necessary for the designer to consider the development of new garments from a life cycle perspective. Applying life cycle does not mean - only evaluating the impacts of a product during its production but also counting the continuous impacts that occur during use and disposal. Designer needs to be mind that improvements made at one stage in the life cycle of a garment should not negatively impact on another stage. It is important that the impact should not be transferred elsewhere. Although garments up cycling or recycling instead of throwing away is positive, but from the perspective of complete life cycle using the clothing longer and not buying new product may be better. Extending lifetimes by recycling or up cycling is challenged by one argument - recycling has also some impact on environment caused by carrying, sorting and selling stages. However, all types of sustainability related effects (environmental, economic and social) are not clear yet.

\subsection{Consumer's action within a garment's life phase and disposal patterns}

It is already discussed in some studies that- the inactive storage is a kind of limbo between inventory and discard. Some studies have discussed maintenance habits and disposal patterns of consumers. Winakor (1969) described the different stages from clothing acquisition to disposal, including use, care and active and inactive storages. VeVerka (1974) showed that when the current use value provided by the garment is less than the current costs of the garment and when the cost of keeping the garment exceeds the costs of disposing of the garment, than from the inactive storage garments are discarded. Why clothes are kept in storage even though they are no longer used was discussed in Cluver's (2008) study concentrating especially on the complex decision making process between storage and disposal. Klepp's (2001) study shows women's clothing habits and reasons for disposal. In her study she identified several reasons for clothing disposal, and divided the reasons for discarding clothes in six main categories-

1. Situational (The owner has developed new consumer needs, such as changed body size, has other similar clothes and not enough of closet space, or that the clothes have too narrow use area)

2. Functional (New and better products have come to the market)

3. Technical or quality related (The product is worn out, ruined or is uncomfortable in use.)

4. Psychological (The owner is tired of the product and wants something new, does not use that style anymore, or clothes do not seem modern)

5. Never worn (Product not suitable for purpose. Often bought on impulse or received as present)

6. Museal (The owner takes the product out of use and keeps it for other purpose, does not want to use it in order to not to ruin it).

By this study it was found that- technical or quality related issue is given as most common reason for clothes disposal, even though a large amount is discarded due to psychological reasons. One of the most psychological reasons is that the owner is bored with the product and wants something new. Another high percentage of disposed clothing is within the sector "never used". Few reasons to this sector could be unsuitable design (fit, use properties) or mistake purchases such as wrong size.

\subsection{Sustainable design}

This is a fundamental requirement that fashion designer and industry, need to engage with the principles of sustainable design. Sustainable design strategies considering life cycle thinking may help the designer to apply a wider range of approaches. Simultaneously if the designer applies life cycle thinking at the design stage and has an understanding of sustainable design strategies, it is then possible to improve the conventional fashion design process.

Fletcher and Goggin (2001) criticize that eco-design is too concentrated on using raw materials in production instead of concentrating on consumer's choices and habits during use phase. However, designers have started considering this issue. To ensure sustainable behavior Lockton et al. (2010) have introduced some tools for design, refer to as "Design with Intent" (DwI). These tools include six different "lenses". The six lenses are a way of grouping design patterns which share similar considerations, behavioral understanding or assumptions about how to influence users. But in Lockton's et al. (2010) lenses are limiting the individual freedom, demographic rights or quality of life. Pettersen and Boks (2008) discuss about this issue and suggest that designers should apply a reflective approach towards the ethical consequences. Today's fashion industry is a combination of high speed and low-cost production with high speed and volume consumption, which puts pressure on working conditions and environmental standards (Fletcher, 2008). Referring to the similarity to fastfood chain McDonalds Lee (2003) has given a new term for this trend, calling it McFashion, because of its low 
price, uniformity and as well as predictability. Designing clothes by considering durability is often seen as a sustainable approach, an antidote to fashion change. In addition by addressing the emotional and expressive qualities during the design process designer could provide eco-design for consumers. This may lead to extended use and a longer functioning cycle (Fletcher, 2008; Hethorn and Ulasewicz, 2008).

Designing attractive products in a user orient way could increase the lifespan. Rosenblad-Wallin (1985) discusses user oriented clothing design projects. She distinguishes between functional values and symbolic values. Symbolic values arise between the user, the product and the socio-cultural environment. Functional values are formed between the user, the product and the actual environment, such as protection and physical comfort. Being inappropriately dressed for an occasion can cause feelings of awkwardness and vulnerability (Entwistle, 2000). The symbolic and aesthetic values of clothing are very important for the wearer to be able to function in social settings (Kaiser, 1997). These values relate the feelings of group membership, respectability, fashion consciousness, decorativeness, and so on. If these facts are not considered well in the design process, the clothes could be unused.

From previous time at last century clothes were individually tailored according to the user's wishes, thus having a high user involvement in the design process. Now a days fashion depends on mass productionmerely receive the fashion information from trend forecasting companies, fashion shows and media (Priest, 2005). However, recently within mass production there is a recent movement towards product customization. In this process consumer could involve within design process (For example Nike iD shoes). This could be a solution for designing product within mass production.

Few studies on clothing sizes and fit have shown that the designers and pattern makers are not always aware about consumers when designing their fashion items. It has been shown that the variation in large women's sizes are many than at small sizes and that large women report more problems with fit (Laitala et al., 2009).This indicates that clothing design includes few goals such as fashionable image creation and designing clothes that only fit to population with ideal body size. According to Oudshoom \& Pinch (2003) some designers consider themselves as users and relay on their personal experiences to be representative for average users which called I-methodology. They claimed this is important for clothes design, where there is a vast diversity of users to reach users in all their variety. More information of consumer habits would be helpful to know more about the designers' option for improving the durability of clothing.

\subsection{Quantitative questionnaire}

\section{Methods}

Quantitative information of consumers' knowledge about sustainable fashion, experiences and opinions about choosing clothes, clothing use, maintenance and disposal habits were collected through a survey in Dhaka. The questionnaire included questions of respondents' social background, shopping habit, clothes disposal habits, and environmental attitudes. All of the questions had multiple answers that the respondent could choose any one. Questionnaires were sent to 500 people of different places in Dhaka. By the date of this analysis, a total of 200 people have responded to the questionnaire.

\subsection{Qualitative consumer's interviews}

Twenty people were selected for a qualitative study to collect more detailed information about their wardrobe through several interviews. In addition to the interviews, they were advised to bring the used clothes and filled in a list along with their purchased clothes during a period of six months. The informants were interviewed a second time to find out the specific reasons for choosing new clothes and disposal of each clothing item. Interview intention was to interview people with different life situations, age, gender, and civil status, so on. The questions were arranged in a format that made the informants describe and reflect on their experiences in a form of a conversation.

\subsection{Technological circumstances and functionality}

\section{Results and Discussion}

In this survey changing shape or size, bubbling, fit issues and poor colorfastness were found as the main reason of disposing clothes. If these problems could be solved, garments would be used longer. Better quality in general, was often commented with wish of better material strength. These typical problems accept sizing problem could be prevented by selecting quality controlled materials, proper sewing and quality control. Increasing user involvement in design and trying on sample patterns on different sized bodies instead of only concentrating on small fit model sizes could be the solution of fitting and size problems; which can increase the use period and lifespan of clothing. 


\subsection{Societal circumstances and fashion}

Social, psychological and situational circumstances are also an important reason for garments disposal. Because of cheap price no emotional attachment and losing interest about garment is one of the most popular reason about disposing. In the purchase situation customer thought they should try some new style or colour they don't usually use and they start buying because of cheap price. And after few days garment lost actual value to the consumer and it became useless and stored for long time. Depending on occasions and materials some visual change of a garment becomes acceptable. For example tear, wrinkle and color fastness in jeans is more acceptable rather than a normal trouser made of other materials. Even sometimes favorite skirts from school time are kept even they are worn out a lot. And in special day or occasion those garments are used by their owner. Due to social reasons, such as that one cannot go to work in same clothing several days in a row, or that the clothing only could be used in some specific occasions such as formal parties. Many samples did not reuse used clothes even if it was only used for some hours and would not have any odor or spot. This problem could be solved through a design solution- by addressing the clothing problem of not being able to use the same clothing several days in a row or at different occasions. In the survey, $60 \%$ of participants said that they would buy sustainable fashion brand's product if that product helps them to feel less need for having something new. Increasing materials quality, developing aesthetics value as well as functionality and variation of style within a garment could be helpful to face these social challenges. Individual designing or customized product could be the one solution. If this idea could apply in mass production it may bring a good change. It is challenging to design hundred percent socially durable products but still material science could be helpful to reduce the frustration among the society. If it is possible to introduce any technology to make visual changes within a garments after using few days like- changing the color and print like the wallpaper of a computer screen, changing the silhouette and shape automatically could be the solution of this societal challenges.

\section{Conclusion}

Through this study it is recommended that designers can play the important role and influence the stages of a garment's lifecycle. Ensuring all ethical decision in use phase of a clothes would not be the consumer's responsibility only but also a brand and designer should take the responsibility. Exploring consumer behavior is important and it can contribute a lot in designer's solution. In this study although it is clear that decision making about a garment's life cycle (include purchasing and disposing decision) is in consumer's hand but still designer and brand can contribute a lot to change this situation by controlling consumer behavior through their brilliant design technique. This study recommended more research is needed to establish a deep design technique. Investigation in several stages of individual level's clothing and clothing life cycle (from cradle to grave) considering consumer behavior should be addressed to facilitate the designer and consumer to contribute in ethical fashion. Functional, symbolic and social requirements have to be addressed in design technique. Researcher and stake holders from several brands could work together in future to facilitate further research and ensure it.

\section{References}

[1]. Black, S., Eckert, C. \& Eskandarypur, F. (2009). The development and positioning of the considerate design tool in the fashion and textiles sector in the centre for sustainable design (ed.). Sustainable Innovation 09: Towards a Low Carbon Innovation Revolution, Famham, University of the Creative Arts. 68-75.

[2]. Cluver, B.G. (2008). Consumer Clothing Inventory Management." Design and Human Environment. Corvallis Oregon State University.

[3]. Fletcher, K. and P.A. Goggin (2001). The Dominant Stances on Ecodesign: A Critique. Design Issues, 17(3), 15-25.

[4]. Fletcher, K. (2008). Sustainable fashion \& textiles Design Journeys. London: Earthscan.

[5]. Hethorn, J. and C. Ulasewicz (2008). Sustainable Fashion: Why Now? : A Conversation Exploring Issues, Practices, and Possibilities. New York: Fairchild Pubns.

[6]. Kaiser, S.B. (1997). The social psychology of clothing. Symbolic appearances in context. New York: Fairchild publications.

[7]. Klepp, I.G. (2001). Hvorfor går klær ut av bruk? Avhending sett i forhold til kvinners klesvaner. Oslo: SIFO.

[8]. Laitala, K., B. Hauge and I.G. Klepp (2009) "Large? Clothing size and size labeling." TemaNord

[9]. 2009:503. Copenhagen: Nordic Council of Ministers.

[10]. Lee, M. (2003). Fashion Victim: Our Love-Hate Relationship with Dressing, Shopping, and the Cost of Style. New York: Broadway Books.

[11]. Lockton, D., D. Harrison and N. Stanton (2010). The Design with Intent Method: A design tool for influencing user behavior. Applied Ergonomics, 41(3), 382-392.

[12]. Oudshoorn, N. and T. Pinch (eds.) (2003). How Users Matter. The Co-construction of Users and

[13]. Technology. Massachusetts: MIT Press.

[14]. Pettersen, I.N. and C. Boks (2008). The ethics in balancing control and freedom when engineering solutions for sustainable behavior. International Journal of Sustainable Engineering, 1(4), 287 - 297.

[15]. Priest, A. (2005). Uniformity and differentiation in fashion. International Journal of Clothing Science and Technology, 17(3/4), 253263.

[16]. Renfrew, E. \& Renfrew, C. 2009. Basics Fashion Design 04: Developing A Collection, AVA publishing SA, Lausanne.

[17]. Rosenblad-Wallin, E. (1985). User-oriented product development applied to functional clothing design. Applied Ergonomics. 16(4), 279-287.

[18]. VeVerka, M.J. (1974). Inactive clothing of selected families. Ames: Iowa state university.

[19]. Winakor, G. (1969). The Process of Clothing Consumption. Journal of Home Economics 61(8), 629-634 